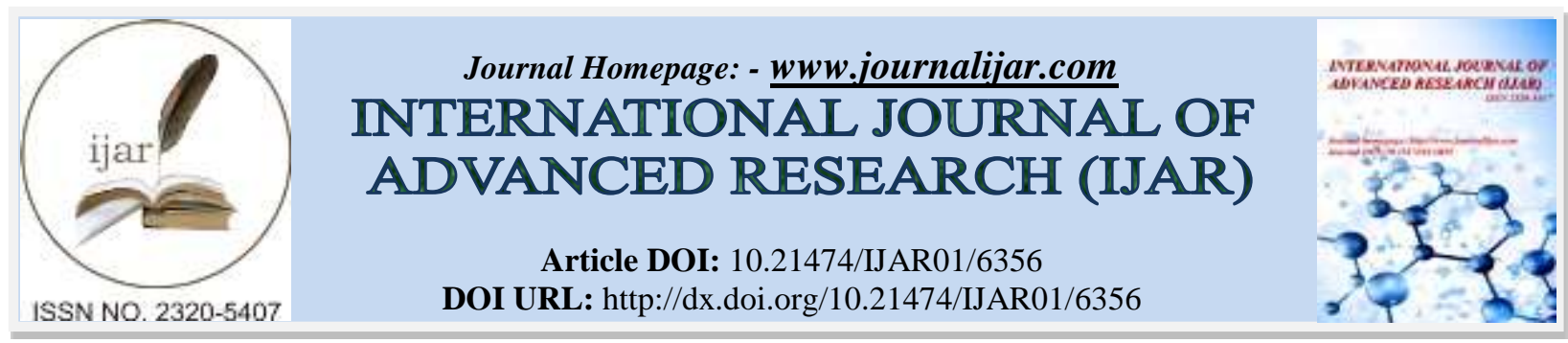

RESEARCH ARTICLE

\title{
SPONDIAS MOMBIN MODULATES GLUCOSE HANDLING MECHANISMS IN TYPE I DIABETIC WISTAR RATS.
}

\section{Ajiboye Kolawole ${ }^{1}$, Ogunsola Abimbola $\mathrm{O}^{\mathbf{1}}$, Agulefo Somto $\mathrm{D}^{\mathbf{1}}$, Ajayi Etseoghena $\mathrm{R}^{\mathbf{1}}$, Ajiboye Oyebimpe $\mathrm{F}^{\mathbf{2}}$} And Oluwole Francis $\mathbf{S}^{3}$.

1. Department of Physiology, Benjamin S. Carson Snr School of Medicine, Babcock University, Nigeria.

2. Department of Radiology, Babcock University Teaching Hospital, Ilisan, Nigeria.

3. Department of Physiology, College of Medicine, University of Ibadan, Ibadan, Nigeria.

\section{Manuscript Info}

(.........................

Manuscript History

Received: 20 November 2017

Final Accepted: 22 December 2017

Published: January 2018

Keywords:-

Spondias Mombin, Diabetes, Glucose

Transporter 4, Adiponectin, Insulin.

\section{Abstract}

A major challenge in diabetic disease is the systemic glucose handling mechanisms with little effort directed at it in the recent past. Spondias mombin is a flowering plant of the anacardiacae family that has been credited with anti-diabetic properties. This study evaluated the antidiabetic activity of S. mombin, its effects on glucose transporter 4 (Glut-4) and adiponectin receptors signalling in streptozotocin-induced diabetic rats.

Adult male Wistar rats $(120-160 \mathrm{~g})$ were randomly divided into 4 groups. Group 1 were normo-glycemic control rats given regular rat chow and water. Group 2 served as negative hyperglycaemic control. Group 3 (High dose) and Group 4 (low dose) served as treatment groups which were pre-treated with $750 \mathrm{mg} / \mathrm{kg}$ and $50 \mathrm{mg} / \mathrm{kg}$ of $\mathrm{S}$. mombin respectively for 21 days. Oral glucose tolerance test (OGTT) and insulin tolerance test (ITT) were done. Glut-4 and adiponectin expression were measured from the supernatant of the gastrocnemius homogenate using ELISA assay. Results were analysed using ANOVA with $\mathrm{p}<0.05$.

Results showed that at low doses, S. mombin modulated the glucose handling capabilities of diabetic rats via an insulin-like acting mechanism. S. mombin also significantly elevated adiponectin expression which has a direct correlation with insulin sensitivity. These effects were not magnified in the high dose group. S. mombin failed to potentiate Glut-4 expression in all tested groups. This study showed that the anti-diabetic activity of S. mombin acts via insulin-like mechanism. This is buttressed by the significant increase in adiponectin expression which is a direct correlate of insulin sensitivity.

Copy Right, IJAR, 2018,. All rights reserved.

\section{Introduction:-}

Diabetes mellitus encompasses a group of disorders with an inability to properly metabolize glucose, leading to the characteristic feature of hyperglycemia. Type 1 diabetes mellitus (also known as insulin dependent diabetes mellitus) is a disease characterized by the selective destruction of insulin-producing beta cells in the islets of 
Langerhans. The exact cause of this destruction is unknown but is suspected to be mediated by cells of the immune system. With an annual incidence rate among people under the age of 20 years of roughly $10-20 \%$ (1 new case per 5000-7000 individual per year). The increase in prevalence of diabetes is expected to be $42 \%$ in developed countries and 70\% in developing countries by 2025 (WHO, 2006; King et al., 1998). It is a terminal disease which is widely spread worldwide. It was formerly believed to be specific to a particular age group but recent studies have shown that it is not age specific but attributable to all age groups. Although symptomatic treatment is available, no cure currently exists for the disease. Thus, the management of diabetes without side effects currently experienced from the prevailing treatment options remains challenge, hence, a growing interest in the evaluation of plant and herbal remedies which are considered less toxic and with minimal side effects.

Spondias Mombin is a tree, a species of flowering plant in the family anacardiaceae. It is commonly known as hog plum. It is a small deciduous tree that grows up to $20 \mathrm{~m}$ high and $1.5 \mathrm{~m}$ in girth, moderately buttressed; bark thick, corky, deeply fissured, slash pale pink, darkening rapidly and branches low. The fruits have a sharp, somewhat acidic taste and are edible. Their flesh surrounds a spiny kernel. It is native to the tropical Americas including the West Indies and has been naturalized in parts of Africa, India, Bangladesh, Sri Lanka and Indonesia. It has been widely credited with a lot of medicinal properties among which are its usage as a diuretic. The bark is used as a purgative, causing relief through vomiting. The leaves are effective for worms in children and can has been applied as an eye lotion. The plant is also useful as an anti-diarrhoeal agent, as an antimicrobial agent, and as an oxytocic and astringent (Oliver- Bever, 1960; Kokwaro, 1976; Abo et al., 1999; Iwu, 1993; Ayensu, 1978). The extract has been documented to have anti-inflammatory activity in Wistar rats. S. mombin also exerts anti-diabetic properties.

\section{Aims and Objectives of The Study:-}

This study was aimed at investigating the mechanism by which S. mombin exerts its anti-diabetic effects. Specifically we investigated the role of S. mombin on Glut4 receptor and adiponectin receptor signalling in streptozotocin-induced diabetic rats. Specific investigation were directed at the following:

1. Possible up or down regulation of Glut4 receptors by S. mombin in streptozotozin-induced diabetic albino Wistar rats.

2. The effect of S. mombin on glucose handling of the streptozotocin-induced diabetic albino Wistar rats.

3. Possible up or down regulation of adiponectin receptor by S. mombin in streptozotozin-induced diabetic albino Wistar rats

\section{Materials and Methods:-}

Twenty (20) male rats weighing between 120-160 grams were procured from a breeding stock maintained in the animal house of the Benjamin S. Carson Snr. School of Medicine, Babcock University. The animals were housed under standard laboratory condition. The animals were maintained under standard photoperiodic condition of 12 hours of light alternating with 12 hours of darkness at the normal room temperature. All the animals were fed with rat chow (Vital feed $\AA$ ) and had access to water ad libitum. They were allowed to acclimatize for 10 days before diabetes induction. The animals were randomly divided into four groups, namely:

Group 1:- (Control) - normo-glycaemic rats given normal chow and water.

Group 2:- (Negative Control) - untreated diabetic control.

Group 3:- (High Dose) - diabetic rats administered $750 \mathrm{mg} / \mathrm{kg}$ B.W of S. mombin extract.

Group 4:- (Low Dose) - diabetic rats administered $50 \mathrm{mg} / \mathrm{kg} \mathrm{B.W}$ of S. mombin extract.

The procedures were performed in accordance with international best practices and convention for animal care and use in education, research and testing. Ethical approval for the study was obtained from Babcock University Health Research Ethical Committee (BUHREC116/15).

\section{Plant Extraction:-}

Leaves of S. mombin were procured within Babcock University environ. They were identified by a plant taxonomist. The leaves were carefully detached from stems through the leaf base, washed and dried in oven at $40^{\circ} \mathrm{C}$ for $48 \mathrm{hrs}$. The leaves were then grinded to fine powder and the active constituent extracted via soxhlet extraction with water as solvent. The liquid extract was filtered through a membrane with suction pressure, concentrated using rotary evaporator and oven at $40^{\circ} \mathrm{C}$ and was stored at $4^{\circ} \mathrm{C}$ till commencement of experiment.

$\%$ yield $=($ weight of yield $/$ weight of raw material $) \times 100$

$=(52 \mathrm{~g} / 578 \mathrm{~g}) \times 100=8.99 \%$

$\%$ yield $=8.99 \%$. 


\section{Experimental Procedures:-}

Animals were fasted for 12 hours but were allowed access to water. Diabetes was induced via intra-peritoneal injection of streptozotocin $(55 \mathrm{mg} / \mathrm{kg} \mathrm{B} . \mathrm{W})$ dissolved in freshly prepared citrate buffer at a $\mathrm{pH}$ of 4.5 . Fasting blood glucose (FBG) was monitored from blood samples collected retro-orbitally by means of a glucometer (ACCUCHEK ${ }^{\circledR}$ Active). A FBG $\geq 150 \mathrm{mg} / \mathrm{dL} 72$ hours after streptozotozin administration was taken as successful diabetes induction. The extract was administered twice daily (morning and evening) with the aid of an oral cannula for a period of 21 days. Oral glucose tolerance test and Insulin tolerance test were also performed.

\section{Oral Glucose Tolerance Test:-}

Oral glucose tolerance test was performed on day 21 by oral administration of $2 \mathrm{~g} / \mathrm{kg} \mathrm{B}$.W of glucose to the rats. Blood was collected from the tail vein every 30 minutes over a three hour period to measure the blood glucose level using a glucometer (ACCU-CHEK® Active) and the clearance rate of glucose from the blood.

\section{Insulin Tolerance Test:-}

This test is carried out in order to determine the level of sensitivity of the cells to insulin. The insulin tolerance test was conducted on day 21 via intra-peritoneal administration of $0.5 \mathrm{mg} / \mathrm{kg}$ B.W of insulin to the rats. Blood was collected every 30 minutes over a two hour period in order to measure the blood glucose levels using a glucometer and to eventually determine the sensitivity of the cells to insulin.

\section{Determination Of Glut-4 And Adiponectin Receptor Expression:-}

The gastrocnemius muscle was harvested from the animals, weighed and placed in ice-cold $0.1 \mathrm{M}$ phosphate buffer solution (PBS) $(0.1 \mathrm{M}, \mathrm{pH}=7.4)$ for homogenisation. The homogenate was spun in a centrifuge at $3000 \mathrm{rpm}$ for 10 minutes and the supernatant was aspirated into clean eppendorff bottles for ELISA. Glut4 and adiponectin expressions were measured from the supernatant using the Enzyme Link Immuno-sorbent assay (Sandwich-ELISA) method.

\section{Statistical Analysis:-}

Data was expressed as Mean \pm SEM

Statistical difference was calculated using ANOVA

$\mathrm{P}<0.05$ was considered as statistically significant.

\section{Results:-}

Table 1:- Showing the concentration of GLUT4 receptors in the control and test groups

\begin{tabular}{|c|c|c|c|c|}
\hline  & Positive control & Negative control & High dose & Low dose \\
\hline $\begin{array}{lll}\text { GLUT } & 4 & \text { receptor } \\
\text { conc }\end{array}$ & $6.31 \pm 0.36$ & $4.80 \pm 0.30^{*}$ & $4.06 \pm 1.21 *$ & $3.80 \pm 0.63 *$ \\
\hline
\end{tabular}

$*=P<0.05$ when compared with the positive control group

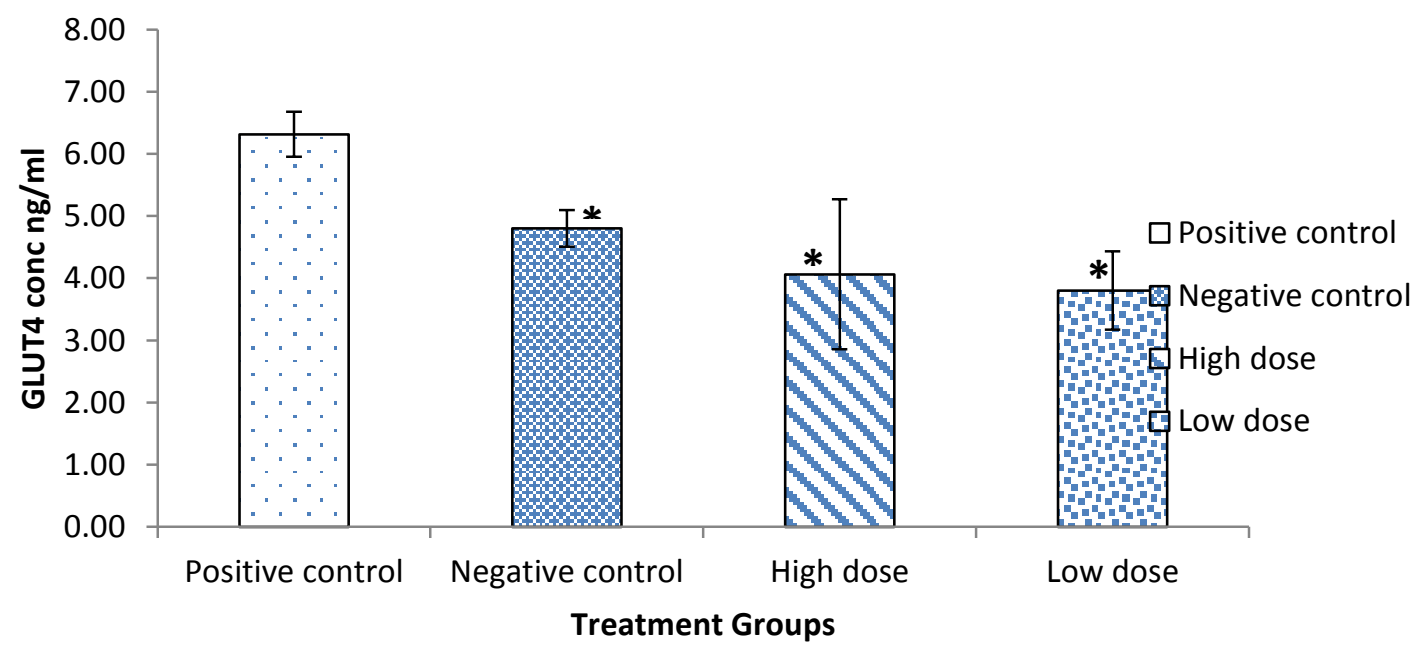

Figure 1:- Effect of Spondias Mombin Extract on concentration of GLUT4 receptors in streptozotocin induced diabetic rats. 


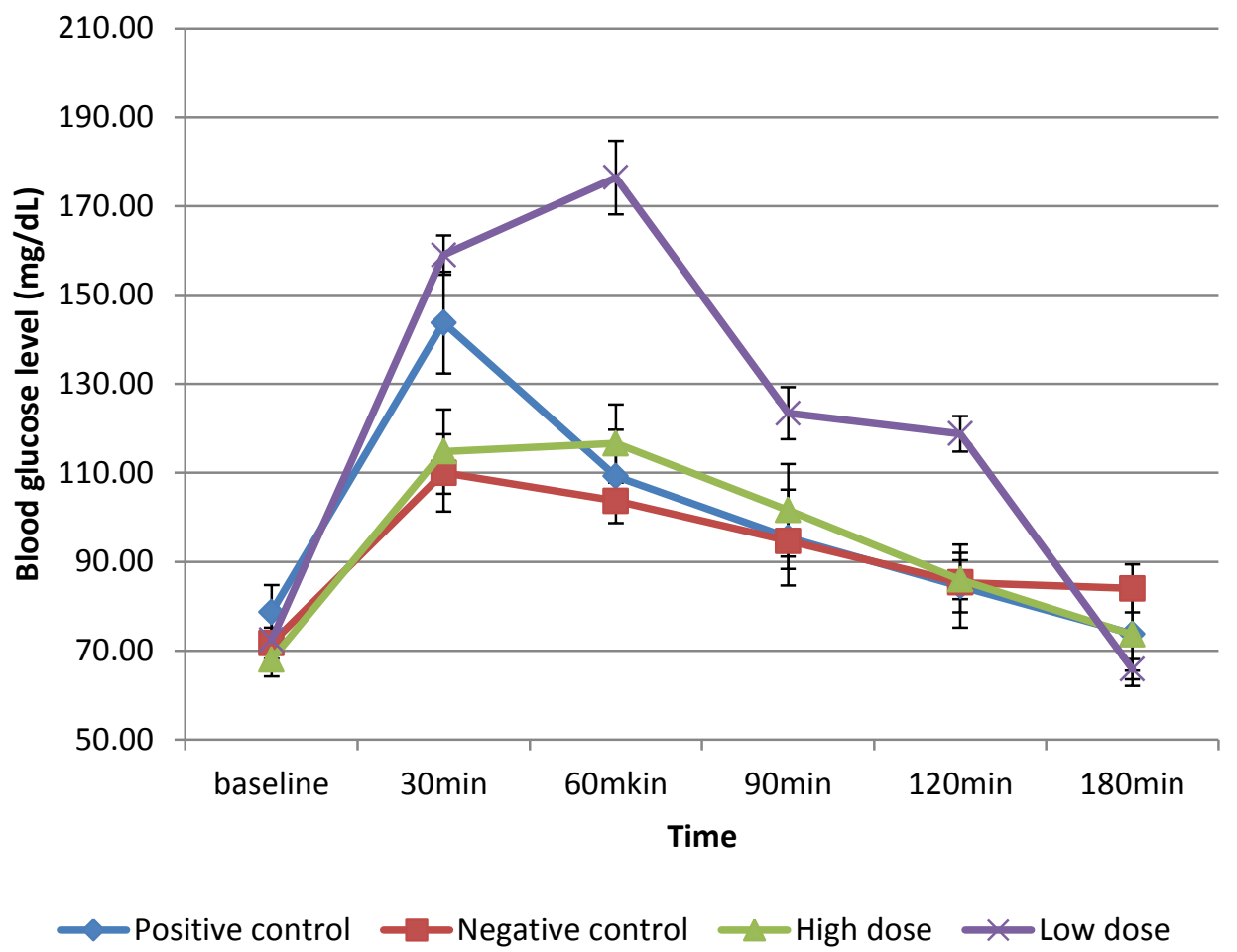

Figure 2:- Effects of Spondias Mombin Extract on oral glucose tolerance test in streptozotocin induced diabetic rats.

Table 2:- Showing area under curve for oral glucose tolerance test in $\mathrm{mg} / \mathrm{dl}$ for oral glucose tests in control and tests groups.

\begin{tabular}{|c|c|c|c|c|}
\hline & Positive control & Negative control & High dose & Low dose \\
\hline OGTT AUC & $17645.55 \pm 558.46$ & $16685.10 \pm 15.75$ & $17088.00 \pm 162.96$ & $22170.00 \pm 7.17 * \# \beta$ \\
\hline
\end{tabular}

$*=\mathrm{P}<0.05$ when compared with the positive control group

$\#=\mathrm{P}<0.05$ when compared with the negative control group

$\beta=\mathrm{P}<0.05$ when compared with the high dose group 


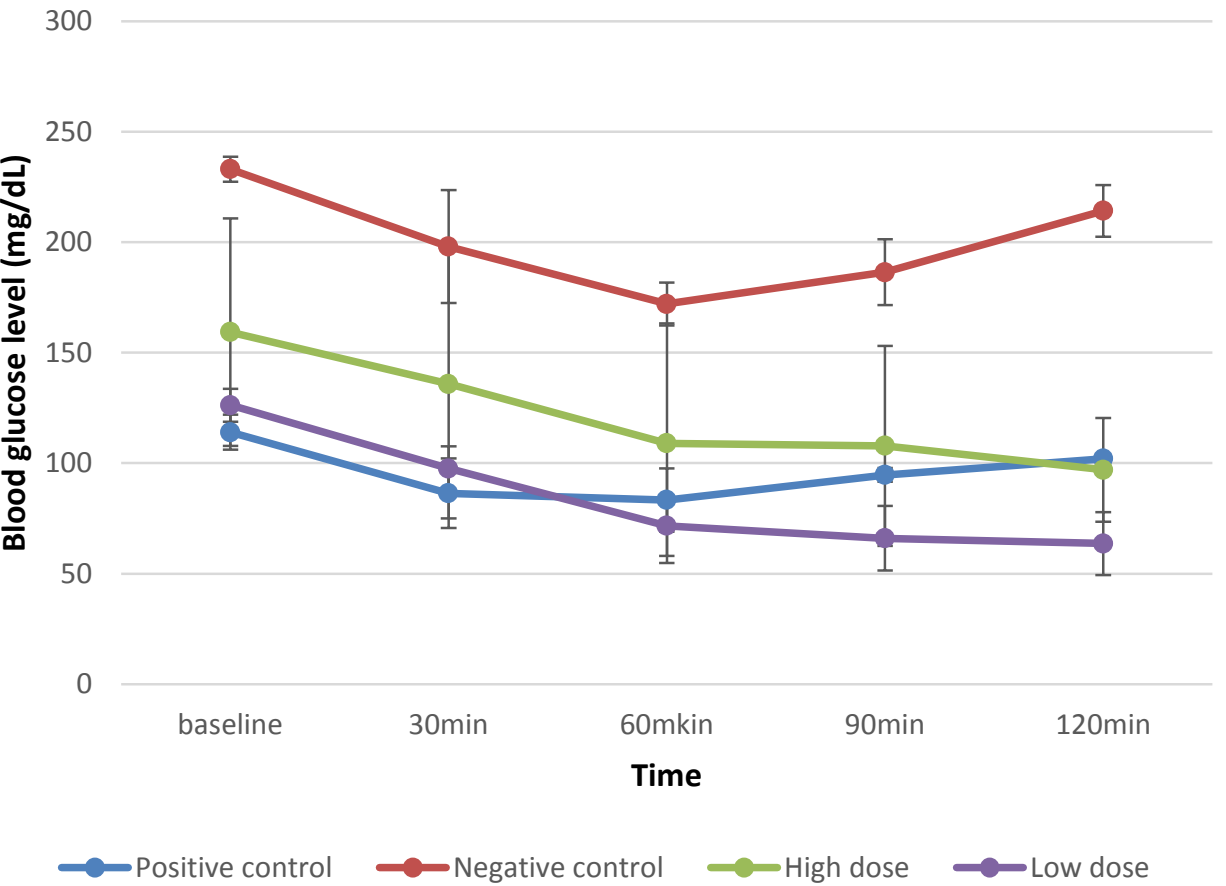

Figure 3:- Effect of Spondias Mombin extract on Insulin tolerance test in streptozotozin induced diabetic rats.

Table 3:- Showing area under curve for insulin tolerance tests in $\mathrm{mg} / \mathrm{dl}$ for insulin tolerance test in control and test groups.

\begin{tabular}{|c|c|c|c|c|}
\hline & Positive control & Negative control & High dose & Low dose \\
\hline ITT AUC & $11169.90 \pm 20.98$ & $23400.00 \pm 80.32$ & $14424.75 \pm 56.04$ & $9903.00 \pm 87.41$ \\
\hline
\end{tabular}

$*=\mathrm{P}<0.05$ when compared with the positive Control group

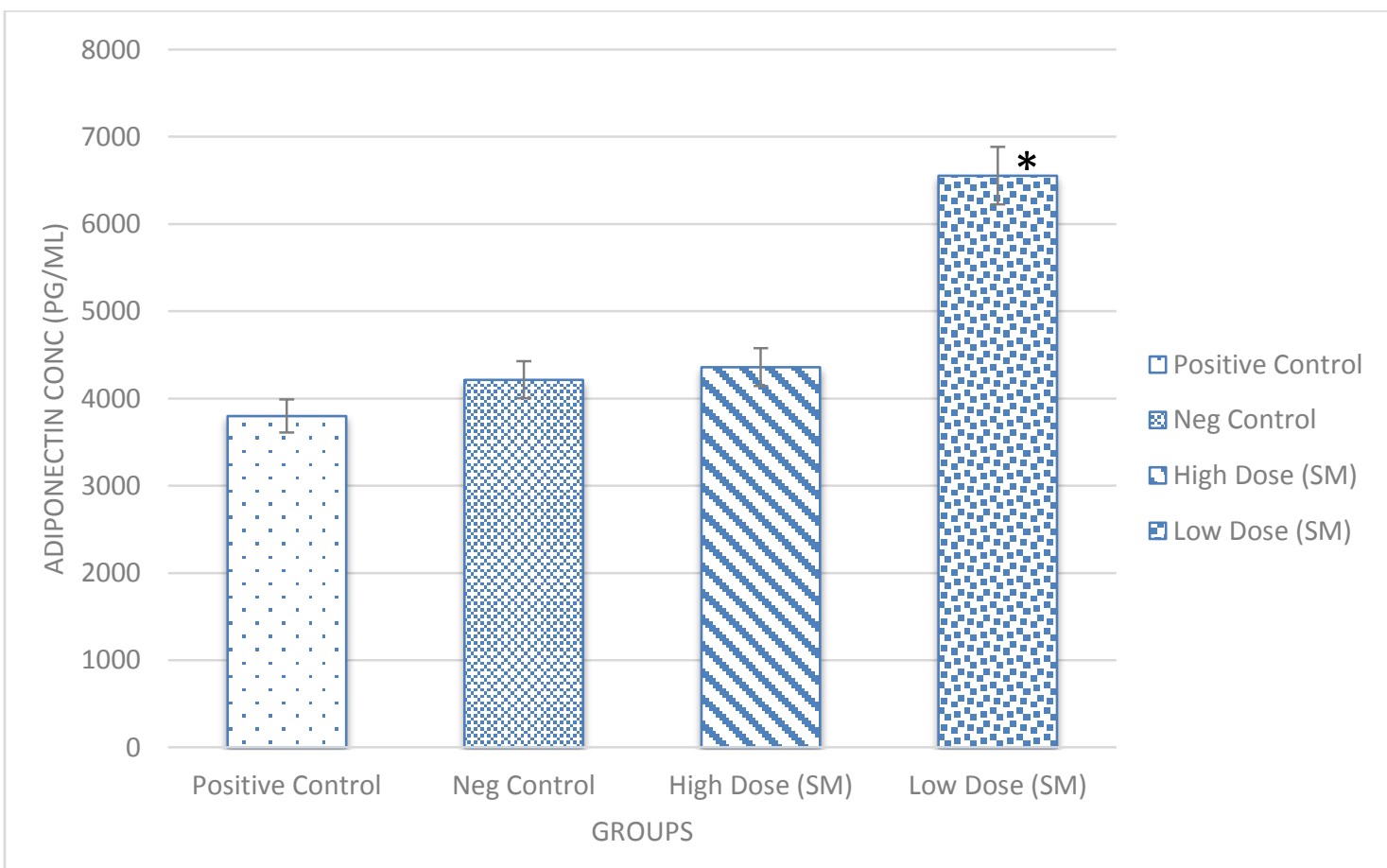

$*=\mathrm{P}<0.05$ when compared with the positive Control group 
Figure 4:- Adiponectin expression in diabetic and S. mombin administered rats.

\section{Discussion and Conclusion:-}

Type 1 diabetes mellitus (DM) has been studied severally using human and animal models in a bid to determine its aetiology, mechanism of action and cellular activities. There exist a lot of contradictory evidences on the specific influence of experimentally induced type $1 \mathrm{DM}$ on glucose transport at the membrane level especially in the skeletal muscle and on GLUT4 receptor concentration in particular. Spondias mombin is an herbal plant that has been credited with anti-diabetic activity in experimentally induced diabetes. Most of its mechanisms of action are however still unknown. This study therefore was an explorative work designed to investigate possible effects of S. mombin administration on GLUT4 and adiponectin receptor expression in streptozotocin-induced diabetic Wistar rats.

Administration of $55 \mathrm{mg} / \mathrm{kg}$ B.W STZ resulted in a disruption of the glucose metabolism through the destruction of the beta cells of the islets of Langerhans of the pancreas. The area under curve for low dose S. mombin in the oral glucose tolerance test (OGTT) was significantly reduced when compared to the other groups (i.e. positive control, negative control and high dose $\mathrm{S}$. mombin $(\mathrm{p}<0.05)$ ). This brings to the fore the argument that at low doses, the extract possess some insulin-like properties. This finding is supported by a previous report by Iweala and Oludare (2011) who stated that the oral administration of methanolic extract of Spondias mombin caused a significant reduction in the blood glucose concentration of diabetic rats. Fred-Jaiyesemi and Kio (2008) also reported that the extract of Spondias mombin showed a significant reduction in blood glucose levels of the type 2 diabetic rats. It was also observed that for the low dose group, there was a significant increase in blood glucose levels up to the 60 minute mark. Thereafter there was a decline up to the 90 minute mark during which a minor plateau was observed before further decline even below base line at the 180 minute mark showing that the glucose present in the body was being handled properly. A similar observation was recorded for the high dose group. The possible mechanism by which the extract of Spondias mombin reduced blood glucose concentration in diabetic rats may be either by increasing the pancreatic secretion of insulin or the release of insulin from bound or conjugated insulin (Pari and Amarnath, 2004). Results from this study buttress the assertion that the aqueous extract of Spondias mombin possibly possess insulin-like properties. The insulin tolerance in the low and high dose S. mombin groups were elevated when compared to the negative control group. From these results, it may be argued that S. mombin extract exhibited insulin-like properties or modulated the secretion of insulin from the beta cells of the islets of Langerhans of the pancreas.

GLUT4 expression is expedient in glucose metabolism as it modulates the movement of glucose into the cell thereby determining the endurance level of the cell. The results show that S. mombin extract had no significant effect on glucose transporter 4 receptor signalling as it neither up-regulated nor down-regulated its concentration in the tissue homogenate assayed. It may therefore be concluded that the mechanism of action of the glucose lowering effect and the insulin-like activity observed in the low dose of the S. mombin extract may not be via activation of GLUT4 channels on the plasma membrane.

The skeletal muscle is a major site of adiponectin action and of glucocorticoid-induced insulin resistance (Jang et al., 2008). Adiponectin presence has been shown to be necessary for glucose homeostasis (Perseglin et al., 2003) and for serving as a marker for insulin sensitivity (Goldstein and Scalia, 2004). Although strongly associated with diabetes of long duration, adiponectin concentration has also been shown to increase with severity of type 1 diabetes (Ljubic et al., 2015). Result from this study showed that adiponectin expression was significantly elevated in the diabetic rat especially in response to low dose S. mombin administration when compared to Control. Adiponectin plays an important role in glucose metabolism by inhibiting fatty acid oxidation which leads to free fatty acid accumulation resulting in insulin resistance as a result of decreased glucose uptake (Sheng and Yang, 2008). Insulin resistance is closely associated with low adiponectin concentration (Le Claire and Palta, 2015). This further buttress the submission that S. mombin possess insulin-like activity given the significantly elevated concentration of adiponectin at low doses of S. mombin.

\section{Conclusion:-}

There is evidence to conclude that the aqueous extract of Spondias mombin at low doses, in addition to showing significant blood glucose reduction properties also possess strong insulin-like property. It modulated insulin secretion and sensitivity which in turn affects glucose homeostasis. Low dose of Spondias mombin also increased 
adiponectin expression in the diabetic rat which has been found to augment insulin action in cells. Spondias mombin extract failed to potentiate GLUT-4 receptor signalling on the plasma membrane.

\section{References:-}

1. Abo K.A., Ogunleye V.O. and Ashidi J.S. (1999): Antimicrobial potential of Spondias Mombin, Croton zambesicus and zygotritonia crocea. Phytotherapy Research., 13, pp 494-497

2. Fred-Jaiyesimi A. and Abo K. (2009): Antidiabetic Activity of Spondias mombin Extract in NIDDM Rats. Pharmaceutical Biology., 47:3, 215-218

3. Goldstein B.J. and Rosario S. (2004): Adiponectin: A Novel Adipokine Linking Adipocytes and Vascular Function. The Journal of Clinical Endocrinology \& Metabolism, Volume 89, Issue 6, Pages 2563-2568

4. Iweala, E.E.J. and Oludare F.D. (2011): Hypoglycemic effect, biochemical and histological changes of Spondiasmombin Linn. and parinaripolyandrabenth. Seed ethanolic extracts in alloxan-induced diabetic rats. J. pharmacol. Toxicol., 6: 101-112.

5. Iwu, M. M. (1993): Handbook of African Medicinal Plants, Boca Raton, p. 435. CRC Press

6. Jang C., Inder W.J., Obeyesekere V.R. and Alford F.P. (2008): Adiponectin, skeletal muscle adiponectin receptor expression and insulin resistance following dexamethasone. Clin Endocrinol., 69 (5):745-50.

7. King H., Aubert R.E. and Herman W.H. (1998): Global burden of diabetes, 1995-2025: prevalence, numerical estimates, and projections. Diabetes Care., 21(9):1414-31.

8. Kokwaro J.O. (1976): Medicinal Plants of East Africa. Nairobi, Kenya: East Africa Literature Bureau. Kampala. p. 384

9. LeCaire, T.J. and Palta, M. (2015): Longitudinal Analysis of adiponectin through 20-Year Type 1 Diabetes Duration," Journal of Diabetes Research., doi: 10.1155/2015/730407

10. Ljubic, S., Anamarija, J., and Martina T. (2015): Inverse Levels of Adiponectin in Type 1 and Type 2 Diabetes Are in Accordance with the State of Albuminuria," International Journal of Endocrinology., vol. 2015. Doi: $10.1155 / 2015 / 372796$

11. Oliver-Bever, B. (1960): Medicinal plants in Nigeria. Being a Course of Four Lectures Delivered in April 1959 in the Pharmacy Department of the Nigerian College of Arts, Science and Technology, Ibadan. p. 760. University of Ibadan press.

12. Pari, L., and Amarnath, S. (2004): Antidiabetic activity of Boerhavia diffusa L. effect on hepatic key enzymes in experimental diabetes. J. Ethnopharmacol., 91,109-113.

13. Perseglin, G., Guido, L., Massimo, D., Lucia, P.S., Paola, M., Francesco De Cobelli, Alberto, B., Antonio, S., Alessandro Del Maschio and Livio, L. (2003): Insulin resistance, intramyocellular lipid content and plasma adiponectin in patients with type 1 diabetes. American Journal of Physiology - Endocrinology and Metabolism., Vol. 285 (6): E1174-E1181

14. Sheng, T. and Yang, K. (2008): Adiponectin and its association with insulin resistance and type 2 diabetes. J Genet Genomics., 35(6):321-6. 